method of keeping the liquid hydrogen container immersed in liquid air, without the disadvantages and technical difficulties which occur if this method is used on a large scale. A drawing of the flask is shown in Fig. 3. It consists of a twin flask ; flask

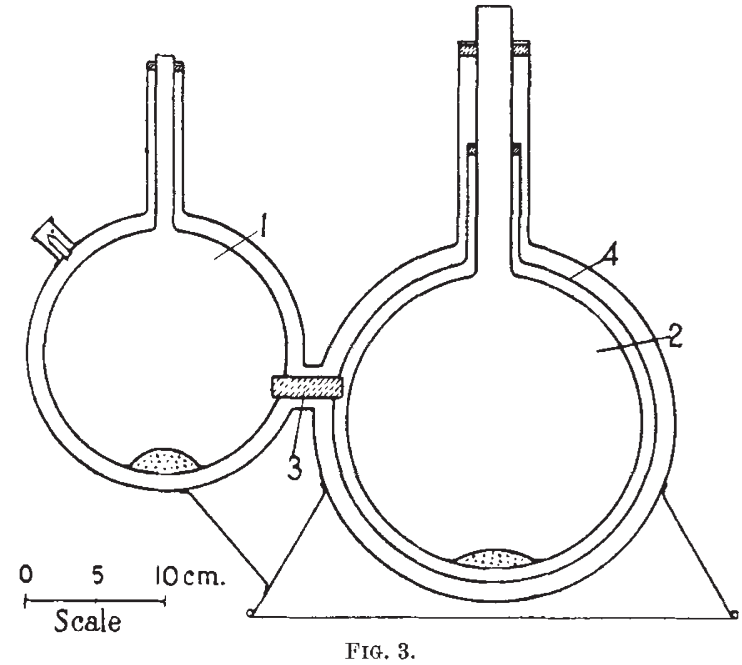

1 contains liquid air, and flask 2 liquid hydrogen. The inside of flask $l$ is connected by means of a copper rod 3 to a copper shield 4 which surrounds the container of flask 2. The liquid air cools the shield 4 by thermal conductivity, and the radiation losses from the liquid hydrogen are considerably reduced. The hydrogen flask has a capacity of 5 litres and the liquid air flask holds 2 litres. The evaporation of hydrogen is about $2.5 \mathrm{gm}$. an hour, which is about seven times smaller than for ordinary flasks, and enables the liquid hydrogen not required for immediate use to remain in the flask for five days. The consumption of liquid air is about 1.7 litres per day. A picture of the flask will be seen in Fig. 2 standing beside the liquefier.

Another flask is now being constructed in which the radiation will be further reduced by silvering the inner surfaces, thereby increasing the efficiency of the flask still further. The flask was manufactured for us by Messrs. Siebe Gorman and Co., Ltd.

The remaining equipment of the Laboratory is on the usual lines, and all the known precautions against explosion are employed, flame-proof mining type motors being used for the compressor drive and all open switchgear placed in a separate room. Besides the usual precautions we have introduced one more, which consists of a standard alarm lamp as used for showing the presence of coal gas in mines. This indicator is manufactured by Messrs. 'The W.R. Patents, Ltd. Should a leak occur, and the concentration of hydrogen in the room reach a value of more than one per cent, the lamp operates a relay which automatically stops the machines, and throws the windows open at the bottom and the top of the rooms where the liquefier is in operation, thus providing a complete air circulation.

We were enabled to construct this plant by a special grant made by the Department of Scientific and Industrial Research.

\footnotetext{
1 “ Handbuch der Physik", vol. 11, p. 295

3 Groeber, “Wärmeübertragung ”, p. 84.
}

\title{
Diagnosis of Smallpox*
}

F $\mathrm{OR}$ adequate control of infectious disease, early and accurate diagnosis is of great importance, but clinical differentiation is not always easy in the early stages. Thus smallpox, even of the severe type, may be mistaken for chickenpox. Some years ago M. H. Gordon described a 'flocculation' test for smallpox, which was later investigated by W. L. Burgess, J. Craigie, and W. J. Tulloch : the last two authors have now extended and amplified the earlier observations. The technique of the test is, in brief, as follows : crusts obtained from the pocks are dried and finely powdered; the powder is extracted with ether and then with saline for some hours ; the mixture is frozen, thawed, and centrifuged to remove particulate matter. Series of dilutions of the extract are made in saline : to one antivaccinia serum is added, to the other normal rabbit serum, and both sets are incubated for about 18 hours at $45^{\circ}-55^{\circ} \mathrm{C}$. Flocculation occurs in the first series at high dilutions of the extract if the crusts were obtained from a case of smallpox, but is not seen in the second series to which normal rabbit serum was added.

The authors carried out an investigation of every step in the test so as to obtain the best conditions :

* Medical Research Council. Special Report Series No. 156: Further Investigations on the Variola-Vaccinia Flocculation Reaction. By J. Craigie and W. J. Tulloch. Pp. 129. (London: H.M. Stationery Office, 1931.) $3 s$. net. thus it was found that more satisfactory results were obtained when the concentration of antiserum was kept constant and that of the antigen (crust extract) varied than when the converse system was employed. For the extraction of the crusts, 0.9 per cent sodium chloride solution was better than weaker concentrations and much more satisfactory than a phosphate buffer solution: in the latter the reaction shifted towards the acid side, whereas that of the saline extracts is remarkably stable. It is essential to carry out the flocculation test at about $p \mathrm{H} 7$ : at $p \mathrm{H} 6$ or 8 non-specific sedimentation is liable to occur. The preliminary extraction with ether removes certain substances which may obscure the test and also reduces the tendency to anomalous flocculation. It has been found further that the flocculable substance is fairly intimately connected with the euglobulin fraction of extracts although it can be to some extent separated therefrom: when the flocculable substance has been destroyed infectivity has also disappeared, but the latter can be markedly reduced without affecting the former. The purified euglobulin fraction is not very stable to heat but is fairly stable to low concentrations of phenol. It is possible to detect by the flocculation test so little as $0.0000005 \mathrm{gm}$. of purified flocculable material.

The flocculation test is positive in smallpox

No. 3250 , VoL. 129] 
(mild or confluent), dermal vaccinia, neurovaccinia, or generalised vaccinia of the rabbit. Out of 195 tests on human material only three (cases of variola minor) gave apparently erroneous results : all crusts from cases of chickenpox were negative. The test is therefore specific and indicates the identity of the infecting virus of smallpox with that of vaccinia (or cowpox, the attenuated virus which is used to develop immunity to smallpox in human beings by 'vaccination'). These results also show that the secondarily infecting bacteria present in dermal material have no influence on the reaction; this conclusion was confirmed by further direct experiments. Thus it was found that crust extracts removed the flocculating property from antivaccinia serum, but failed to remove the staphylococcal agglutinating bodies from antistaphylococcal serum; and that absorption with suspensions of secondarily infecting bacteria had no effect on the flocculating properties of anti-vaccinia serum although such absorption rendered inert the antisera specific to the secondarily infecting organisms.

An antiserum such as is used for the flocculation test appears to exert a specific antibody action on the virus in vitro. After four hours incubation at $37^{\circ} \mathrm{C}$. of a mixture of serum and virus the latter is inactivated or destroyed, since no lesion is produced on dermal inoculation: destruction is theoretically unlikely and probably does not actually occur since infection may be produced if inoculation is made into the rabbit's testes.
On the other hand, evidence was obtained that passive immunity to vaccinia could be produced in rabbits and guinea-pigs by the injection of antivaccinia serum possessing flocculating properties. The immunity of the animals was tested by dermal, testicular, and intravenous inoculation of virus: the results did not depend on the serum or strain of virus used.

As a natural sequel to the above results, attempts were made to produce immunity by the use of virus sensitised with antiserum. It was found that such a mixture, although failing to 'take' on dermal inoculation, produced, on subcutaneous injection into rabbits, a very high degree of immunity. The importance of this observation lies in the fact that it may be possible to produce immunity in human beings by this method without the risk, small though it is, of the development of the sequelæ, such as vaccinal encephalitis, which occasionally follow ordinary 'vaccination'. The theoretical objection to the use of sensitised virus is that although the antiserum may control the infection at the site of injection, it may be powerless to do so if the virus is disseminated: the authors are carrying out further investigations on this point. In any event, the results of the experiments on the production of passive immunity suggest that it might be possible to immunise smallpox contacts so that the disease would be aborted even in circumstances when vaccination might fail to prevent infection.

\section{Obituary}

Mr. Louts Brennan, C.B.

$\mathrm{B}^{\mathrm{Y}}$ $Y$ the death of Louis Brennan on Jan. 17, at Montreux, Switzerland, Great Britain loses an inventor whose name was once very widely known. Born at Castlebar, Ireland, on Jan. 28, 1852, Brennan at an early age went to Australia, and it was while working as a watchmaker in Melbourne that he conceived the idea for a torpedo which could be fired and controlled from a fixed position.

Assisted by a member of the staff of the University of Melbourne, towards the end of the seventies of last century Brennan succeeded in arousing the interest of Government officials, and in 1880 the Admiralty appointed a committee of naval officers serving on the Australian station to report on the torpedo. Their report being favourable, Brennan was brought to England, and as the torpedo was considered very suitable for the defence of creeks and harbours, the matter was taken up by the War Office, Brennan being attached to the Royal Engineers at Chatham, and a torpedo factory being built at Gillingham. Brennan was at first given a retaining fee of $£ 5000$ and a salary of $£ 2000$. He superintended the factory for many years, and from 1896 until 1907 was retained as consulting engineer.

Like Whitehead's automobile torpedo, Brennan's machine was fish-shaped and had fins, horizontal and vertical rudders, hydrostatic depth control, and double propellers, but it was driven and con- trolled by two wires running over drums driven by a steam engine in the firing station and connected with other drums in the body of the torpedo.

At Gillingham, Brennan began his work on the monorail locomotive with gyroscopic stabilisers. His model, now in the Science Museum, South Kensington, was described in the technical press in 1907, and a public trial of his car took place at Gillingham on Nov. 10, 1909. The car was $40 \mathrm{ft}$. long, $10 \mathrm{ft}$. wide, and $13 \mathrm{ft}$. high, and had a wheel base of $20 \mathrm{ft}$. and a weight of 20 tons. It ran on a single rail track, which included a circular path 200 yards round, and successfully carried a party of 40 persons. It was fitted with two petrol engines driving electric generators supplying current to the driving motors, and to two large gyroscopes which preserved the balance of the car in all circumstances. Each gyroscope had a wheel weighing three-quarters of a ton, revolving at 3000 r.p.m. in a casing from which the air was exhausted. On the day of trial, owing to one of the generators being out of action, a speed of only 7 miles an hour was attained, but the designed full speed was 35 miles an hour. Brennan himself envisaged a monorail car $150 \mathrm{ft}$. long and $25 \mathrm{ft}$. wide travelling at about twice the speed of existing railway trains, but his invention did not lead to any development.

During the War, Brennan served with the Ministry of Munitions and later with the Air Ministry, and

No. 3250, VoL. 129] 